\section{Policing animal experiments}

SiR-A letter from Mr Clive Hollands appeared in Nature $(339,248 ; 1989)$ stating that experiments published in this journal earlier in the year $(337,265 ; 1989)$ would have been illegal had they been carried out in the United Kingdom. It took two weeks for Nature to point out that this was an expression of opinion and not legal fact $(339,407 ; 1989)$. Your error in publishing the letter without proper consideration was compounded by the inappropriate and emotive heading for your leading article ("Beastly experiments") the following week. This headline puts Nature in the same category as The Sun and Sunday Mirror. The antivivisection campaign of the Sunday Mirror against Professor Colin Blakemore was recently investigated by the Press Council, which found that the basis of the campaign was false and required the publication of that adjudication.

Unfortunately, much of the subsequent correspondence (for example Nature 340, $180 ; 1989)$ seems to have taken more notice of Hollands' incorrect assertion than of your belated article setting out the correct position. It is important that your readers, whatever their personal opinions about the use of animals for research, should know that in the United Kingdom there is a new Animals (Scientific Procedures) Act (1986) which controls the use of such animals. All scientists in the United Kingdom using animals for research must hold a personal licence and be covered by a separate project licence, both issued by the Home Secretary after appropriate application and consideration. Section 5(4) of the Animals (Scientific Procedures) Act (1986) states: "In determining whether and on what terms to grant a project licence the Secretary of State shall weigh the likely adverse effects on the animals concerned against the benefit likely to accrue as a result of the programme to be specified in the licence". The experiments Hollands complains of have not been put to the Home Secretary and therefore it is not known whether they would be allowed in the United Kingdom. Hollands is a member of the Animal Procedures Committee that advises the Home Secretary on matters relating to the licensing of scientists to carry out animal experiments. He therefore knows or should know what the law states. There is good reason to believe that Hollands was advised before sending his letter to Nature that it would be inappropriate for him to claim that these experiments would be illegal in the United Kingdom.

Nature has done a great disservice to biomedical research in this country. You should attempt to repair the damage by a proper apology to the French scientists whose work you have effectively repudi- ated and by a discussion of the likely adverse effects on both medical and fundamental research of your too ready acceptance of an antivivisectionist's minority viewpoint. Blakemore has been and still is the subject of an aggressive personal attack by antivivisectionists. This attack now appears to be spreading to his colleagues around the world. Their work on the development of the visual system is of the highest order and has led to important advances in the understanding of both basic mechanisms and clinical problems that may arise in the young. It is high time that Blakemore and those other scientists, who have been pilloried for their work by a tiny but aggressive minority, were properly and publicly supported by international organs of communication such as Nature, and by government and charitable organizations that provide much of the financial support for research involving animals.

\section{Department of Physiology \& \\ Pharmacology, \\ University of Southampton, \\ Southampton SO9 3TU, UK}

\section{Reprints' function}

SIR-In spite of the plethora of letters to Nature regarding the pros and cons of honouring reprint requests, a major point seems to have been missed by those against. Gone are the days when a scientist could make a leisurely trip to the library, leaf through the three or four journals of interest to him/her, and photocopy the few articles of interest. There has been a tremendous 'information explosion' in both the number of journals in any particular field and the number of articles. To a scientist who wishes to maintain any breadth of knowledge, even within a highly restricted field, this is simply no longer possible. It would require two or three days each week of exclusive library work.

That increasing numbers of scientists are making use of commercial computer searches and associated reprint requests is a reflection of this change within the scientific community. It is neither a reflection of laziness nor of selfishness on the part of the reprint requesters, as suggested by Peter Johnson (Nature 339, 170; 1989). Rather, it is a reflection of time economy, combined with a desire to keep up with the literature.

On the other hand, some scientists, according to Johnson, apparently resent the "throwing [of] the burden of time and cost onto the author". The time taken to mail reprints is considerably less than in searching out an article and mailing it, especially as most requests are accom- panied by easily used return addresses. Thus the real problem appears to be the cost. This seems to me to be a predictable cost that granting agencies are willing to accept as an appropriate item on a budget. For those without grants, it could be an item for negotiation with their departments as an administrative cost as essential to any science department as writing paper or secretarial support.

Scientific endeavours are meaningless if not communicated to others in the appropriate scientific community. Given the nature of contemporary science, the problem of this communication (of which the honouring of reprint requests is an important element) is not a trivial issue. Perhaps it is time for the recognition of the necessity of the dissemination of scientific information, and a general agreement as to whose shoulders the responsibility for this dissemination should fall upon.

Department of Psychiatry, MATHEW T. MARTIN-IVERSON

\section{University of Alberta,}

\section{E7 44 W Mackenzie Health Sciences}

Centre,

Edmonton, Canada T6G $2 B 7$

SIR-On the question of reprint requests, many Russian scientific journals are translated into English from cover to cover, but authors usually have no free reprints of the translated papers and so cannot usually satisfy reprint requests. The authors can only send reprints of the Russian originals.

BORIS V. SHESTOPALOV

Institute of Cytology,

Academy of Sciences of the USSR, Leningrad 194064, USSR

\section{No to South Africa}

SIR-I am one of those who have stuck their necks out and said "No" to science from South Africa. I have done it because I believe that the inviolateness of the practice of science is not absolute; its precedence is relative and must be judged against the enormity of the racial injustice in that country. Racial injustice is being practised in many countries, but it is the scale of it in South Africa that stands out. One of the arguments against boycotting South African science is that it harms innocent scientists. I would weigh this against the harm being suffered by millions of innocent blacks at the hands of a much smaller number of whites. If the black leaders believe that sanctions and boycotts will help to change their situation for the better, then I will support them in this way. Who else should we listen to but the victims?

JOHN ORMEROD

Department of Biology,

University of Oslo,

PO Box 1050, Blindern,

N-0316 Oslo 3, Norway 